Check for updates

Cite this: RSC Adv., 2017, 7, 21258

Received 28th February 2017

Accepted 7th April 2017

DOI: $10.1039 / \mathrm{c} 7 \mathrm{ra02509b}$

rsc.li/rsc-advances

\section{Enzymatic synthesis of an electrospinnable poly(butylene succinate-co-dilinoleic succinate) thermoplastic elastomer $\uparrow$}

\author{
Agueda Sonseca and Miroslawa El Fray (iD *
}

\begin{abstract}
Candida antarctica lipase B was successfully employed for the first time as a biocatalyst to obtain high molecular weight poly(butylene succinate-co-dilinoleic succinate) (PBS: DLS) copolyester via a twostage method in a diphenyl ether solution from diethyl succinate, 1,4-butanediol, and dimer linoleic diol. The final hard to soft segments were close to the initial feed ratio as confirmed by ${ }^{1} \mathrm{H}$ NMR and FTIR measurements. Thermal analysis revealed the presence of two transitions typical for thermoplastic elastomers: a low temperature glass transition and high temperature melting point. In addition, the optimized synthetic protocol ensured high reaction yield $(>74 \%)$ and molecular weight $\left(M_{\mathrm{w}}>34 \times 10^{3} \mathrm{~g}\right.$ $\mathrm{mol}^{-1}$ ) high enough to process the copolymer into electrospun mats without defects. The enzymatically synthesized PBS: DLS was able to be processed at 20-25 w/v\% concentrations into fibres and depending on the type of solvent, the fibre diameter was controlled in the range of 0.3 to $0.6 \mu \mathrm{m}$.
\end{abstract}

\section{Introduction}

There is an increasing demand for degradable polymers for tissue engineering applications that can be processed into three-dimensional synthetic porous scaffolds. This has led to a great deal of research focused on the synthesis of new aliphatic polyesters and copolyesters with different properties and structures for this target application. ${ }^{\mathbf{1} 2}$ Fibrous scaffolds are favoured for tissue engineering, because of their ability to mimic the structure and properties of the extracellular matrix (ECM), such as anisotropic mechanical properties, interconnected porosity, and high surface area to volume ratio. This approach maximizes the space for cell attachment and tissue ingrowth, decreasing the amount of polymer implanted and, at the same time, encouraging effective diffusion and distribution of the cells. ${ }^{3}$ Towards this aim, electrospinning is a relatively simple technique that provides a straightforward way to produce nano- and microfiber mats for the fabrication of tissue engineered scaffolds. ${ }^{4}$

One of the main applications of these scaffolds is for soft tissue replacements such as myocardium or blood vessels. Ideally, the scaffold should mimic the mechanical properties of native tissues ${ }^{5}$ thus, elastomeric materials are preferred as they will possess more suitable properties to work in a cyclic loading environment matching the behaviour of native tissues.

Division of Biomaterials and Microbiological Technologies, Polymer Institute, Faculty of Chemical Technology and Engineering, West Pomeranian University of Technology, 45 Piastów Ave, 70-311, Szczecin, Poland.E-mail: miroslawa.elfray@zut.edu.pl

$\dagger$ Electronic supplementary information (ESI) available. See DOI: $10.1039 / \mathrm{c} 7 \mathrm{ra02509b}$
In this regard, biodegradable elastomers offer an attractive alternative to non-elastomeric biodegradable polymers currently used for many soft-tissue engineering applications. Several types of biodegradable elastomeric materials have been reported in the literature, ${ }^{6,7}$ but their main disadvantage is the need to use reinforcing/crosslinking agents, stabilizers or cure systems along with compounding. ${ }^{8,9}$ Therefore, just a few reports present the fabrication of elastomeric scaffolds obtained by electrospinning, with the need of be processed by blends or sacrificial polymers. ${ }^{10,11}$

To overcome these drawbacks, a big deal of research has been focused in the development of new thermoplastic elastomers (TPE) as they are the most versatile family of elastomeric materials, thanks to having many of the physical properties of crosslinked elastomers (rubbers) and being processed as thermoplastics. TPEs are (multi)block copolymers composed of thermodynamically incompatible segments built up from rigid (hard) thermoplastic components and soft elastomeric components. This results in microphase separation and formation of a discrete micro- (or nano-) domain structure that stabilizes the system-no need for curing or stabilizing agents.

Poly(butylene succinate) (PBS) is one of the most significant members of the aliphatic polyester family. As its properties can be easily tailored by copolymerization, ${ }^{\mathbf{1 2 , 1 3}}$ it has promising applications as a hard segment building block in bioabsorbable/ biocompatible materials for medical purposes. Recently, PBS was used for the synthesis of TPEs, constituting the hard segments in multiblock copolymers, while dimer linoleic acid (DLA) or dimer linoleic diol (DLA-OH) units were used as the soft segments component. Our group has reported on the controlled biodegradability and promising biocompatibility of these 
materials. ${ }^{\mathbf{1 4 , 1 5}}$ By varying the PBS to DLA (hard to soft segment) ratio, poly(butylene succinate-co-butylene dilinoleate) (PBS : DLA) copolymers covering a wide range of mechanical properties and degradation rates can be synthesized. Importantly, by using dimer linoleic diol (DLA-OH) as soft segment building block instead of dimer linoleic acid (DLA), poly(butylene succinate-co-dilinoleic succinate) multiblock copolymers with interesting elastomeric behaviour at body temperature can also be obtained. ${ }^{10}$ Therefore, this approach holds the promise for biodegradable and biocompatible medical materials able to mimic the elasticity of human tissues with excellent compliance.

Additionally, electrospinning of elastomeric neat poly(butylene succinate-co-butylene dilinoleate) (PBS:DLA) and poly(butylene succinate-co-dilinoleic succinate) (PBS : DLS), as well as their blends with poly(glycerol sebacate), has been reported to produce scaffolds with properties well-suited for cardiac tissue engineering applications. ${ }^{\mathbf{1 0 , 1 5}}$

While PBS : DLA and PBS : DLS copolymers represent good candidates materials for tailorable scaffolds that mimic the elastic properties of soft tissues ECM, most of the approaches to the synthesis of PBS and its copolymers involve the use of organometallic catalysts at high reaction temperatures $(\geq 200$ $\left.{ }^{\circ} \mathrm{C}\right) .{ }^{16}$ As a result, undesirable degradation and side-reactions can occur due to the high temperature, especially when using thermally or chemically unstable monomers (i.e. siloxane, epoxy and vinyl moieties). ${ }^{17}$ Further, difficulty to remove residual metals from the catalyst, that strongly interacts with the ester groups, limits their applications as medical materials. ${ }^{18}$ Finally, environmental concerns are driving demand not only for materials from renewable resources instead of fossil fuels, but also for the use of non-toxic catalysts in the polymer synthesis.

The "green chemistry" approach, ${ }^{\mathbf{1 9 , 2 0}}$ is an emerging field including the use of enzymes as catalysts for polymerization reactions of new polymers, as well as modification/ functionalization of existing polymers. Enzymes as polymerization catalysts have been extensively used to produce a variety of useful materials such as polysaccharides, polyesters, polycarbonates and polyamides. ${ }^{21-23}$ The main advantages of enzymes are related to their versatility as a catalysts: they provide higher enantio-, regio-, and chemoselectivity, are able to lower the activation energy of chemical reactions to operate at mild temperature conditions, and are derived from renewable resources. As a result, enzymatic catalysis provides an effective platform for conducting green polymer chemistry to obtain environment-friendly synthetic process for polymeric materials. Among all the enzymes as a catalyst, Candida antarctica lipase B (CAL-B) is the most widely employed in transesterification and esterification reactions because of its reactivity and high stability in many organic solvents even at elevated temperatures. ${ }^{24}$ This approach has been extensively used in transesterification reactions to obtain polyesters and copolyesters from a broad range of substrates. ${ }^{25-28}$ However, although the enzyme-catalyzed materials are extraordinarily advantageous from a toxicity and environmental point of view, the formation of relatively low molecular weight polyesters represents a major drawback especially in the case of the formation of copolyesters. It limits the processability of the obtained polymeric materials into any useful physical form, such as films or electrospun nano/microfiber porous scaffolds for tissue engineering. ${ }^{29}$

With this background and based on our experience with organometallic synthesis of PBS : DLS copolymers, the objective of this work was to utilize Candida antarctica lipase B (CAL-B) as a catalyst to synthesize poly(butylene succinate-co-dilinoleic succinate) (PBS : DLS) copolymer based on dimer linoleic diol (DLA-OH), with a $70: 30 \mathrm{wt} \%$ ratio of hard to soft segments. Importantly, the polymerization conditions were optimized in order to achieve a copolymer with sufficiently high molecular weight to fabricate porous scaffolds by electrospinning.

\section{Experimental}

\section{Materials}

Dichloromethane (DCM: $\geq 99.5 \%$ ), diethyl succinate (DS: $\geq 99 \%$ ), 1,4-butanediol (BD: 99\%) and diphenyl ether ( $\geq 99 \%$ ) were purchased from Sigma Aldrich (Poznan, Poland). Dimer linoleic diol (DLA-OH) Pripol ${ }^{\text {TM }} 2033$ (dimer alcohol $\geq 96.5 \%$ ), was purchased from Croda Coatings \& Polymers, Gouda (The Netherlands). Chloroform $\left(\mathrm{CHCl}_{3}\right.$ : $\left.\geq 98.5 \%\right)$ was purchased from POCh (Gliwice, Poland), Tetrahydrofuran (THF: $\geq 99.5 \%$ ), $N, N$-dimethylformamide (DMF: $\geq 99.8 \%$ ) and methanol (MeOH: $\geq 99.8 \%$ ), were purchased from POCh (Gliwice, Poland). Lipase B from Candida antarctica (CAL-B), covalently immobilized on polyacrylate beads $\left(300-500 \mu \mathrm{m}>95 \%\right.$, Fermase CALB $\left.{ }^{\mathrm{TM}} 10000\right)$, with a nominal activity of 10000 PLU per g (propyl laurate Units per gram dry weight), was purchased from Fermenta Biotech Ltd. Mumbai and kindly provided from Enzyme Catalyzed Polymers LLC, Akron, OH. Diphenyl ether was stored over $4 \AA$ molecular sieves and CAL-B was dried at $40{ }^{\circ} \mathrm{C}$ under vacuum for $18 \mathrm{~h}$ prior to use. The other chemicals were used as received.

\section{General procedure for CAL-B-catalyzed synthesis of PBS : DLS copolymer via two-stage method in diphenyl ether}

CAL-B (10 wt\% of total monomers) was added to a magnetically stirred solution containing 1,4-butanediol (BD, $1.56 \mathrm{~g}, 17.31$ $\mathrm{mmol}$ ), diethyl succinate (DS. $3.36 \mathrm{~g}, 19.30 \mathrm{mmol}$ ), and dimer linoleic diol (DLA-OH, $1.08 \mathrm{~g}, 1.99 \mathrm{mmol}$ ) in diphenyl ether (200 $\mathrm{wt} \%$ of total monomers), in a three-necked round-bottom flask, placed in an oil heating bath equipped with a condenser. The amount of the monomers was calculated in order to obtain a multiblock copolymer with poly(butylene succinate) sequences constituting the hard segments and succinate-dimer linoleic diol sequences constituting the soft segments, in approximately $70: 30 \mathrm{wt} \%$ segment ratio composition. The reaction protocol was adapted and modified from ref. 30 and the two following transesterification stages were performed (Scheme 1): (1) the first step was carried out at the initial temperature of $80{ }^{\circ} \mathrm{C}$ under $\mathrm{N}_{2}$ flow at atmospheric pressure. After 1 hour, when the reaction mixture was homogeneous and the CAL-B was well dispersed in the media, the temperature was slowly increased to $95{ }^{\circ} \mathrm{C}$. The collection of ethanol was monitored until half of the theoretical amount of this by-product was collected (2-3 h) and further oligomerization was carried out under 600 torr for $18 \mathrm{~h}$; (2) in the second step, the pressure was reduced to 2 torr while 


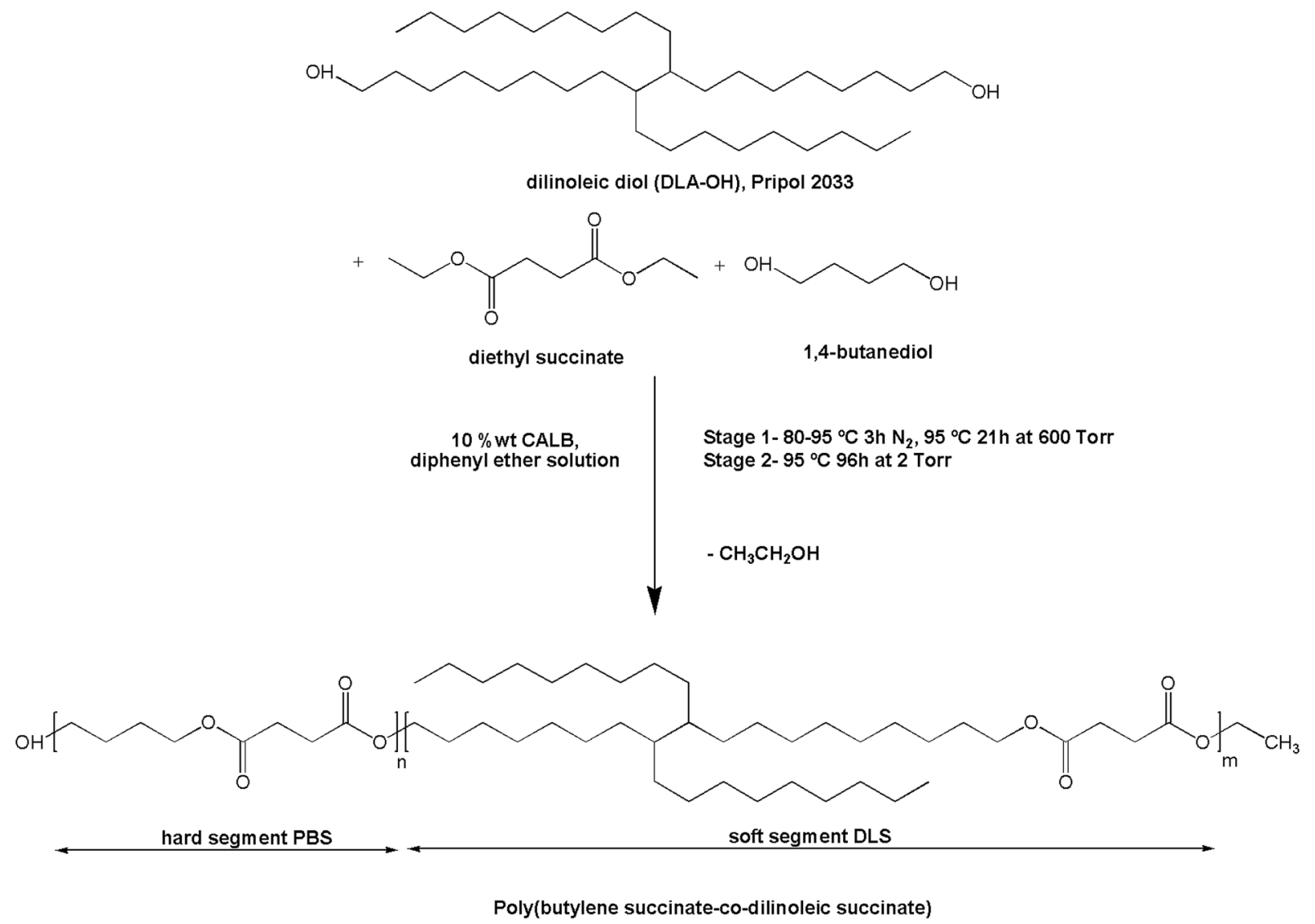

Scheme 1 Synthesis conditions for the transesterification of dilinoleic diol, diethyl succinate and 1,4-butanediol catalyzed by CALB to form poly(butylene succinate-co-dilinoleic succinate) copolymer.

maintaining the reaction at $95^{\circ} \mathrm{C}$ for $84 \mathrm{~h}$. Upon completion, the formed product was dissolved in chloroform, the catalyst was removed via filtration and the chloroform solution was concentrated in a rotary evaporator and purified by dropwise precipitation into cold methanol under continuous stirring. The precipitated polymer was filtered, thoroughly washed with cold methanol, collected, and dried under vacuum (225 torr) at $40{ }^{\circ} \mathrm{C}$. No residual solvent from the synthesis stage was detected in the ${ }^{1} \mathrm{H}$ NMR and FTIR spectra. The reaction yield was $>74 \%$ as calculated from the initial weight of the monomers and the weight of the obtained product after precipitation and drying, taking into account the amount of ethanol collected during the synthesis (step 1).

\section{Characterization of PBS : DLS copolymer}

The chemical structure of the obtained copolymer was verified by nuclear magnetic resonance $\left({ }^{1} \mathrm{H}\right.$ NMR) and infrared spectroscopy (ATR-FTIR). The ${ }^{1} \mathrm{H}$ NMR (128 scans, 1 second relaxation delay) and ${ }^{13} \mathrm{C}$ NMR (5120 scans, 1 second relaxation delay) spectra were recorded in $\mathrm{CDCl}_{3}$ on a TM Bruker DPX $400(400$ $\mathrm{MHz}$ ) spectrometer using tetramethylsilane (TMS) as internal reference. The composition was determined by ${ }^{1} \mathrm{H}$ NMR from the ratio of the integrals of the signals associated with the butylene units arising from PBS hard segments at $1.76 \mathrm{ppm}(4 \mathrm{H})$ and dimer linoleic diol of the DLS soft segments at $4.12 \mathrm{ppm}$
$(6 \mathrm{H})$. FTIR transmission spectra was recorded using a Bruker ALPHA spectrometer with an Attenuated Total Reflectance (ATR) cell between 400 and $4000 \mathrm{~cm}^{-1}$, with a $2 \mathrm{~cm}^{-1}$ resolution. Samples were vacuum-dried prior to measurement, and 32 scans were averaged across the spectral range. The intrinsic viscosity $([\eta])$ was determined in chloroform at $25{ }^{\circ} \mathrm{C}$ in an Ubbelhode viscometer $(K=0.00342)$, and the results were calculated using the Solomon-Ciuta equation. ${ }^{31}$ The numberaverage molecular weight $\left(M_{\mathrm{n}}\right)$, weight-average molecular weight $\left(M_{\mathrm{w}}\right)$, and polydispersity index (PDI) of the PBS : DLS copolymer were determined by gel permeation chromatography (GPC). The experiment was conducted on a Tosoh EcoSEC, equipped with 2 fused silica separation columns and four detection systems: Dual Absorbance UV (UV, Waters 2487, wavelength $\lambda=254 \mathrm{~nm}$ ), multi-angle laser light scattering (MALLS, Wyatt mini-DAWN Treos), refractive index (RI, Wyatt OPTILAB DSP), and viscometer (VIS, Wyatt ViscoStar-II). The results were analyzed using ASTRA 6 software (Wyatt Technology). The sample concentration was $2-3 \mathrm{mg} \mathrm{mL}^{-1}$ and $\mathrm{CHCl}_{3}$ (HPLC grade, Alfa Aesar), continuously distilled from $\mathrm{CaH}_{2}$, was used as eluent at a flow rate of $0.7 \mathrm{~mL} \mathrm{~min}^{-1}$; the injected volume was $15 \mu \mathrm{L}$. The run time was $60 \mathrm{~min}$, in order to avoid the aftereffect of the viscometer in the differential refractive index (dRI) signal. The incremental refractive index $(\mathrm{d} n / \mathrm{d} c)$ was calculated from the concentration and calculated mass, 
assuming $100 \%$ mass recovery from the columns. The thermal behaviour of PBS : DLS was studied in a TA Instruments DSC Q100 differential scanning calorimeter. Measurements were carried out in a heating-cooling-heating cycle over the temperature range from -90 to $200{ }^{\circ} \mathrm{C}$, at a heating/cooling rate of $10{ }^{\circ} \mathrm{C} \mathrm{min}^{-1}$, under a $\mathrm{N}_{2}$ atmosphere. The glass transition temperature $\left(T_{\mathrm{g}}\right)$ was calculated as the midpoint of the transition in the second heating run. The crystallinity content $\left(X_{\mathrm{c}} \%\right)$ was calculated as crystallization degree of hard phase evaluated according to the following equation:

$$
X_{\mathrm{c}} \%=\left(0.7 \times \Delta H_{\mathrm{m}} / \Delta H_{\mathrm{m}}^{0}\right) \times 100
$$

where $\Delta H_{\mathrm{m}}$ is the melting enthalpy, and $\Delta H_{\mathrm{m}}^{0}$ is the reference $\Delta H_{\mathrm{m}}\left(110.3 \mathrm{~J} \mathrm{~g}^{-1}\right)$ of $100 \%$ crystalline PBS.

\section{Electrospinning process}

In order to investigate the ability of the enzymatically synthesized PBS : DLS 70 : 30 copolymer to be processed by electrospinning, different solution concentrations and solvents were tested to optimize the process. Solvents tested included DCM, $\mathrm{CHCl}_{3}, \mathrm{DMF}, \mathrm{THF}, \mathrm{MeOH}$ and their mixtures. All solutions were electrospun using a standard horizontal electrospinning setup. First, all air bubbles were purged and then a syringe pump was used to fee the solutions into the tip of a needle (21 gauge) directly connected to a high voltage power supply. The solutions were electrospun over a grounded flat stainless steel collector covered with aluminium foil. The optimized electrospinning parameters, solution concentration and solvent system were used to produce a thicker uniform nanofiber mat $(60 \pm 6.1 \mu \mathrm{m})$ without structural defects.

\section{Characterization of PBS : DLS scaffolds}

Morphological analysis of the electrospun fibers was carried out by means of scanning electron microscopy (SEM, JEOL JSM 6100). Samples were sputtered with gold and observed at $10 \mathrm{kV}$ with a working distance of 14.4-15.7 mm. Fibre diameters were calculated as an average of 30 random measurements over at least two SEM micrographs at $2500 \times$ magnification using the ImageJ software (National Institute of Health, USA). A thicker mat was electrospun with experimentally found and optimized parameters and solvent system, and its thermal and mechanical properties were evaluated. The thermal behaviour was studied by using a differential scanning calorimeter (DSC, TA Instruments Q100) under the same conditions as previously described for the bulk material. In addition, the elongation at break, Young's modulus and maximum tensile strength were measured at room temperature by static tensile tests on a universal testing machine (Instron 3366, Instron Co., Ltd., USA) equipped with a $500 \mathrm{~N}$ load cell. The measurements were carried out at the crosshead speed of $1 \mathrm{~mm} \mathrm{~min}^{-1}$ from 0 to $0.5 \%$ elongation and of $10 \mathrm{~mm} \mathrm{~min}^{-1}$ from $0.5 \%$ elongation.
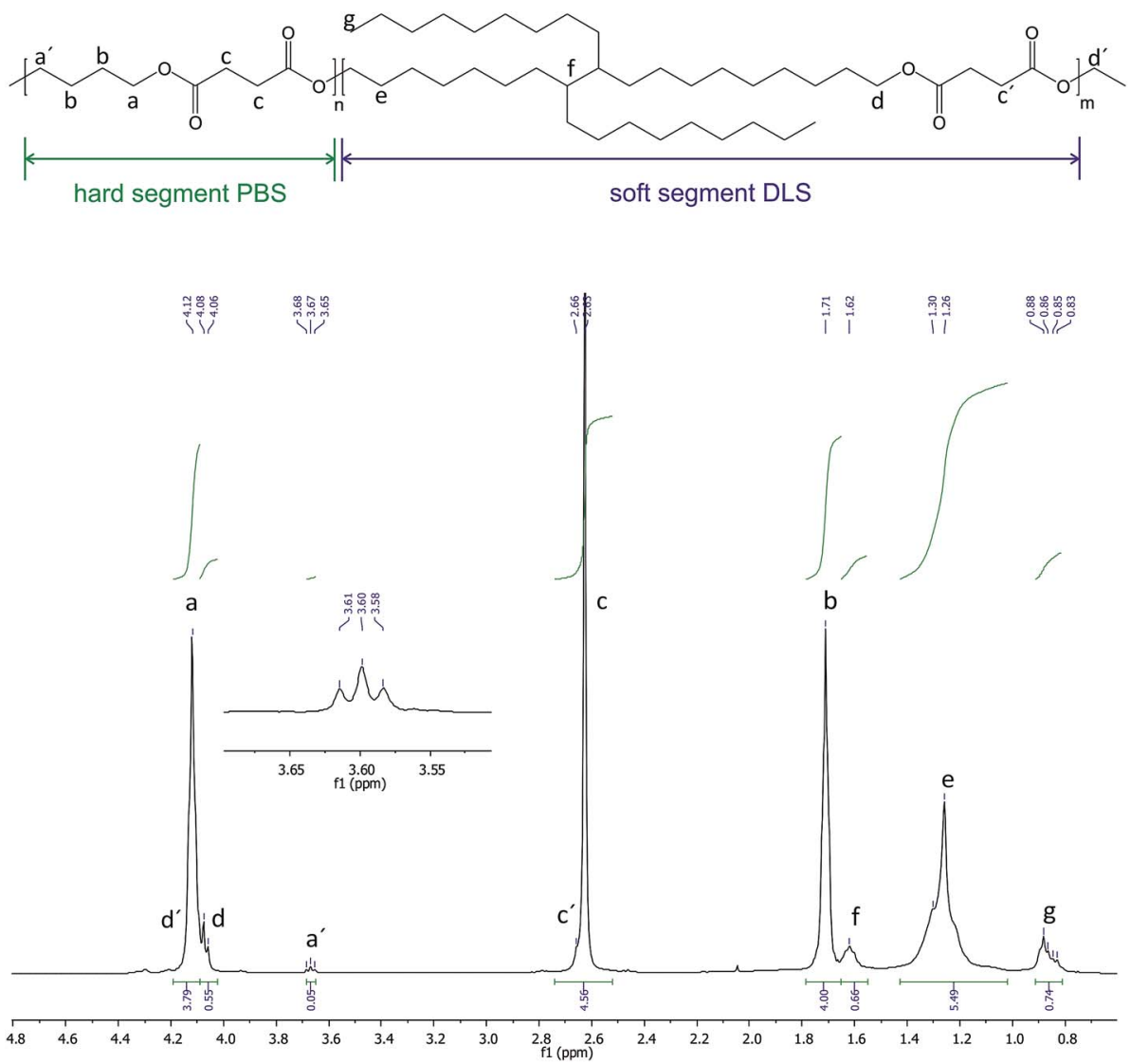

Fig. $1{ }^{1} \mathrm{H}$ NMR of the poly(butylene succinate-co-dilinoleic succinate) $70: 30$ copolymer. 
Sample dimensions were typically $5 \mathrm{~mm}$ wide, $50 \mu \mathrm{m}$ thick and $4 \mathrm{~cm}$ long while the length between clamps was $2 \mathrm{~cm}$. Thickness was measured by using a coating thickness gauge (Elcometer Instruments $\mathrm{GmbH}$, Germany) with Elcometer thickness standards, the mechanical data is an average of the six specimens.

\section{Results and discussion}

\section{Characterization of PBS : DLS 70 : 30 copolymer}

The synthesis of PBS : DLS 70 : 30 copolymer was achieved via two-step transesterification process using CAL-B as a catalyst and performed in diphenyl ether solution. The first step of the reaction under $\mathrm{N}_{2}$ and subsequently low vacuum is thought to prevent monomer loss due to evaporation to allow their conversion into non-volatile oligomers. The stepwise decreasing of the vacuum to avoid premature loss of monomers and oligomers at the early stage of the synthesis, together with the high vacuum during the second step that facilitates the removal of the ethanol by-product, as well as the high boiling point of diphenyl ether (allowing for high vacuum without loses) and its high octanol/water partition coefficient $(\log P=4.21)$ (lipase activity is reported to be improved at higher $\log P$ than 1.9$)^{32,33}$ resulted in the convenient promotion of the copolymer chain growth. ${ }^{30}$ In addition, other commercial forms of the CAL-B immobilized on macroporous acrylic resin particles have been proved to retain good activity at high temperatures in such a solvents as diphenyl ether $(>80 \%$ of normalized activity at $100{ }^{\circ} \mathrm{C}$ after $24 \mathrm{~h}$ in diphenyl ether). ${ }^{33}$ Therefore, one must consider that all the aforementioned conditions led to the formation of a high molecular weight copolyester, helping to the reaction system to remain soluble with well dispersed catalyst and without a significant drop in its activity along the reaction time. Scheme 1 summarizes the general synthesis conditions for the transesterification of DS with BD and DLA$\mathrm{OH}$, to form poly(butylene succinate-co-dilinoleic succinate) (PBS : DLS) copolymer. Fig. S1-S3 (ESI $\dagger$ ) show some possible structures as well as ${ }^{1} \mathrm{H}$ NMR and ${ }^{13} \mathrm{C}$ NMR spectra of the commercial PRIPOL 2033 DLA-OH employed, and are explained there in detail. The structure of the enzymatically synthesized PBS : DLS copolymer is depicted in Fig. 1 and its characteristics are given in Table 1 . The composition was determined from ${ }^{1} \mathrm{H}$ NMR confirming a final wt $\%$ and molar\% composition of hard to soft segments close to the initial feed ratio, confirming that sufficient losses of monomers were

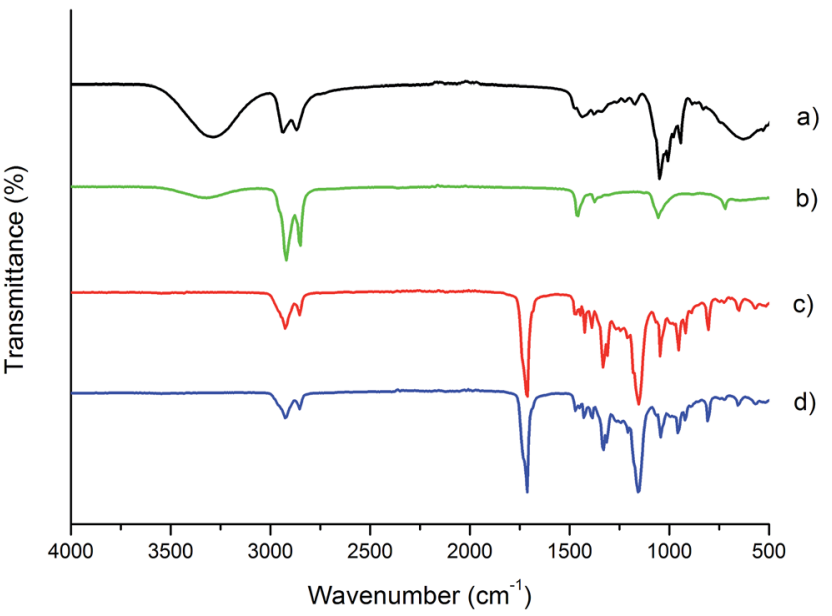

Fig. 2 FT-IR spectrum of: 1,4 butanediol (a), Pripol 2033 (b), PBS : DLS $70: 30$ polymer after precipitation and drying (c) and PBS : DLS $70: 30$ after electrospinning from a $25 \mathrm{w} / \mathrm{v} \%$ in $\mathrm{a} \mathrm{CHCl}_{3}: \mathrm{MeOH}$ solution (d).

avoided with the stepwise decrease of the pressure during the reaction. In ${ }^{1} \mathrm{H}$ NMR, signals appearing at $\delta^{1} \mathrm{H}=4.09-4.11 \mathrm{ppm}$ (a) are due to the methylene protons of BD segment attached to the oxygen, confirming the reaction between the BD and DS. Methylene protons of DS and the rest from BD appear at $\delta^{1} \mathrm{H}=$ $2.61 \mathrm{ppm}(\mathrm{c})$, and $\delta^{1} \mathrm{H}=1.65-1.73 \mathrm{ppm}(\mathrm{b})$, respectively. The signals at $\delta^{1} \mathrm{H}=4.04-4.08 \mathrm{ppm}$ (d) are due to the methylene protons of DLS segment adjacent to the ester bond confirming the transesterification reaction between the DLA-OH and the DS. The tertiary carbon protons appear at $\delta^{1} \mathrm{H}=1.57-1.63 \mathrm{ppm}$ (f), methylene groups of DLA appear around $\delta^{1} \mathrm{H}=1.25 \mathrm{ppm}(\mathrm{e})$ and methyl end groups appear at $\delta^{1} \mathrm{H}=0.87 \mathrm{ppm}(\mathrm{g})$. The low intensity resonances at $\delta^{1} \mathrm{H}=3.64-3.68 \mathrm{ppm}\left(\mathrm{a}^{\prime}\right)$ are due to the proton signals from the BD methylene units at the end of PBS$\mathrm{OH}$ hard segment chain end groups. Note that no residual signal of unreacted hydroxyl groups from DLA-OH were observed in the ${ }^{1} \mathrm{H}$ NMR spectra $\left(\delta^{1} \mathrm{H}=3.61-3.64 \mathrm{ppm}\right)$. The protons from the DS methylene units at the end of the soft segment chain are not easily visible as they appear in the region near to $\delta^{1} \mathrm{H}=4.11 \mathrm{ppm}$ where the methylene protons of butanediol are present. Fig. S4 and S5 (ESI $\dagger$ ) shows the ${ }^{13} \mathrm{C}$ NMR spectra of the PBS : DLS $70: 30$ copolymer. The two different methylene carbons next to the oxygen in the ester bonds appear at $\delta^{13} \mathrm{C}=64.94 \mathrm{ppm}(\mathrm{h})$, due to the reaction between DLA-OH

Table 1 Characteristics of the synthesized PBS : DLS copolymer

\begin{tabular}{|c|c|c|c|c|c|c|c|c|c|}
\hline \multirow[b]{2}{*}{ Sample } & \multicolumn{2}{|c|}{$\begin{array}{l}\text { Experimental } \\
\text { conditions }\end{array}$} & \multicolumn{7}{|c|}{${ }^{1} \mathrm{H}$ NMR } \\
\hline & $\begin{array}{l}\mathrm{Hs} / \mathrm{Ss} \\
(\mathrm{mol} \%)\end{array}$ & $\begin{array}{l}\mathrm{Hs} / \mathrm{Ss} \\
(\mathrm{wt} \%)\end{array}$ & $\begin{array}{l}\mathrm{Hs} / \mathrm{Ss}^{a} \\
(\mathrm{~mol} \%)\end{array}$ & $\begin{array}{l}\mathrm{Hs} / \mathrm{Ss}^{a} \\
(\mathrm{wt} \%)\end{array}$ & $\begin{array}{l}\mathrm{DP}^{a} \\
{[\mathrm{Hs}]}\end{array}$ & $\begin{array}{l}M_{\mathrm{w}}{ }^{b} \\
\left(10^{3} \mathrm{~g} \mathrm{~mol}^{-1}\right)\end{array}$ & $\begin{array}{l}M_{\mathrm{n}}{ }^{b} \\
\left(10^{3} \mathrm{~g} \mathrm{~mol}^{-1}\right)\end{array}$ & $\begin{array}{l}M_{\mathrm{w}} / \\
M_{\mathrm{n}}{ }^{b}\end{array}$ & $\begin{array}{l}{[\eta]} \\
{\left[\mathrm{dl} \mathrm{g}^{-1}\right]}\end{array}$ \\
\hline Bulk PBS : DLS $70: 30$ & $89.7 / 10.3$ & $70 / 30$ & $89 / 11$ & $68.5 / 31.5$ & 40 & 34.7 & 12.8 & 2.7 & 0.56 \\
\hline
\end{tabular}


Table 2 Thermal transitions of the synthesized PBS : DLS copolymer (powder) and its electrospun fibers from a $25 \mathrm{w} / \mathrm{v} \%$ in a $\mathrm{CHCl} 3 \mathrm{:} \mathrm{MeOH}$ solution $^{a}$

\begin{tabular}{|c|c|c|c|c|c|c|c|}
\hline Sample & $T_{\mathrm{c}}\left({ }^{\circ} \mathrm{C}\right)$ & $T_{\mathrm{g}}\left({ }^{\circ} \mathrm{C}\right)$ & $T_{\mathrm{m}}\left({ }^{\circ} \mathrm{C}\right)$ & $\Delta H_{\mathrm{c}}\left(\mathrm{J} \mathrm{g}^{-1}\right)$ & $\Delta H_{\mathrm{m}}\left(\mathrm{J} \mathrm{g}^{-1}\right)$ & $\Delta H_{\mathrm{m}}^{0}\left(\mathrm{~J} \mathrm{~g}^{-1}\right)$ & $X_{\mathrm{c}}(\%)$ \\
\hline Powder PBS : DLS $70: 30$ & 51.1 & -44.2 & 100.4 & 54.4 & 51.2 & 110.3 & 32.5 \\
\hline Fiber PBS : DLS $70: 30$ & 48.5 & -42.7 & 100.3 & 63.0 & 59.5 & 110.3 & 37.7 \\
\hline
\end{tabular}

${ }^{a} T_{\mathrm{c}}$ - crystallization temperature, $T_{\mathrm{g}}$ - glass transition of soft segments, $T_{\mathrm{m}}$ - melting point of hard segments, $\Delta H_{\mathrm{c}}-$ crystallization enthalpy; $\Delta H_{\mathrm{m}}-$ melting enthalpy; $\Delta H_{\mathrm{m}}^{0}$ - melting enthalpy of $100 \%$ crystalline PBS, $X_{\mathrm{c}}$ - degree of crystallization of hard phase from DSC.

and DS, and at $\delta^{13} \mathrm{C}=64.17 \mathrm{ppm}(\mathrm{a})$, due the reaction between $\mathrm{BD}$ and DS. These facts together with the disappearance of the signal at $\delta^{13} \mathrm{C}=63.02 \mathrm{ppm}$, related to the carbon attached to the $-\mathrm{OH}$ ending of DLA-OH (Fig. S3, ESI $\dagger$ ), as well as the shifting up-field of the $(\mathrm{g})$ signal $\left(-\mathrm{CH}_{2} \mathrm{CH}_{2} \mathrm{OH}\right.$, from $32.81 \mathrm{ppm}$ to $-\mathrm{CH}_{2} \mathrm{CH}_{2} \mathrm{O}$ - at 28.58), indicate the formation of the desired structure of the copolymer as well as the incorporation of the DLA-OH between DS units. The signal at $\delta^{13} \mathrm{C}=172.29 \mathrm{ppm}(\mathrm{d})$ is due to the $-\mathrm{CO}-$ from DS attached to DLA-OH, and signals at $\delta^{13} \mathrm{C}=29.02 \mathrm{ppm}(\mathrm{b})$, and $\delta^{13} \mathrm{C}=25.21 \mathrm{ppm}(\mathrm{c})$ are due to the $-\mathrm{CH}_{2}-$ from DS and BD units, respectively. Low intensity signals due to end-groups were detected at $\delta^{13} \mathrm{C}=62.2 \mathrm{ppm}, \delta^{13} \mathrm{C}=$ $29.09 \mathrm{ppm}, \delta^{13} \mathrm{C}=25.06 \mathrm{ppm}$ and $\delta^{13} \mathrm{C}=64.57 \mathrm{ppm}$ from $\mathrm{OHCH}_{2} \mathrm{CH}_{2} \mathrm{CH}_{2} \mathrm{CH}_{2} \mathrm{O}-$ of $\mathrm{BD}$ and at $\delta^{13} \mathrm{C}=172.37 \mathrm{ppm}\left(\mathrm{d}^{\prime}\right)$ from $-\mathrm{COCH}_{2} \mathrm{CH}_{3}$ and at $\delta^{13} \mathrm{C}=14.19 \mathrm{ppm}$ (o) from $-\mathrm{COCH}_{2}$ $\mathrm{CH}_{3}$ of DS. The signal at $\delta^{13} \mathrm{C}=14.4 \mathrm{ppm}$ is related to the $-\mathrm{CH}_{3}$ from DLA-OH and the rest of the signals at $\delta^{13} \mathrm{C}=22.69$ $31.92 \mathrm{ppm}$ are related to the aliphatic chain from DLA-OH.

Fig. 2 shows the ATR-FTIR spectra of BD and DLA-OH (Fig. 2a and b) monomers and the obtained copolymer processed into electrospun mat (Fig. $2 \mathrm{c}$ and d). As can be seen from Fig. 2c (PBS : DLS 70:30 bulk material), the ester formation and the presence of polymerized DLA-OH units is confirmed and is in agreement with ${ }^{1} \mathrm{H}$ NMR results. The characteristic absorptions bands for carbonyl-stretching vibrations $(\mathrm{C}=\mathrm{O}$, $\left.1713 \mathrm{~cm}^{-1}\right)$ and $\mathrm{C}-\mathrm{O}-\mathrm{C}$ stretching $\left(1153 \mathrm{~cm}^{-1}\right)$ of the ester groups in the polymer backbone confirm the successful formation of a polyester. Comparing the spectra for DLA-OH (Fig. 2b) and PBS : DLS copolymer (Fig. 2c), it can be seen that the predominant bands at $2923 \mathrm{~cm}^{-1}$ and $2854 \mathrm{~cm}^{-1}$ correspond to the methylene groups $\left(-\mathrm{CH}_{2}-\right)$ of the aliphatic long chain soft segments due to the polymerized DLA-OH that at the same time overlap the bands from aliphatic chain $(-\mathrm{CH}-)$ from hard segments. The lack of an absorbance band between 3400 and $3500 \mathrm{~cm}^{-1}$ in the copolymer spectra confirms the reaction of the hydroxyl groups from DLA-OH (Fig. 2b) and BD (Fig. 2a)-no $\mathrm{OH}$ functionality remains.

The number-average molar mass $\left(M_{\mathrm{n}}\right)$ and number-average molecular weight $\left(M_{\mathrm{w}}\right)$ of the copolyester were estimated by GPC as $12.8 \times 10^{3} \mathrm{~g} \mathrm{~mol}^{-1}$ and $34.7 \times 10^{3} \mathrm{~g} \mathrm{~mol}^{-1}$ respectively, holding a polydispersity index (PDI, $M_{\mathrm{w}} / M_{\mathrm{n}}$ ) of 2.7 (Table 1). Although high molecular weight poly(butylene succinate) homopolymer has been achieved under similar conditions, ${ }^{30}$ just a few reports attempted to enzymatically synthesize copolymers under similar conditions and based on poly(butylene succinate), either with poly $((R)-3 \text {-hydroxybutyrate })^{34}$ or dimethyl itaconate. ${ }^{35}$ Moreover, for the first time, the enzymatic transesterification between poly(butylene succinate) (PBS), and a fatty dimer alcohol is presented and processed in a useful morphology, suitable for potential biomedical applications on account of the sufficient molecular weight obtained.

In general, the electrospinnability of low molecular weight polymers is strongly limited due to the low amount of molecular entanglements between polymeric chains in solution. ${ }^{36,37}$ Usually, high molecular weight or high concentrations improve the electrospinning of the polymers favouring the formation of fibres instead of drops. ${ }^{38}$ Thus, the obtained molecular weight is expected to ensure the electrospinnability of the system using typical solution concentrations for similar copolymers previously synthesized with organometallic catalysts. ${ }^{\mathbf{1 0}}$

Finally, the thermal properties for the bulk-synthesized copolymer are in agreement with the previous results, confirming that the desired material was obtained. Importantly, as can be seen from Fig. S6 (ESI $\dagger$ ) and Table 2, the low temperature $T_{\mathrm{g}}$ of soft segments and high temperature melting $T_{\mathrm{m}}$ of hard segments indicate the formation of thermoplastic segmented elastomer. Additionally, the characteristic temperature transitions reported here for the enzymatically synthesized bulk material are comparable to those of PBS : DLS 70 : $30 \mathrm{wt} \%$ hard to soft segments ratio synthesized previously in our laboratory using $\mathrm{Ti}(\mathrm{BuO})_{4}$ organometallic catalyst. ${ }^{10}$

\section{Characterization of electrospun mats}

It is well-known that the success of forming polymeric fibres during the electrospinning process depends strongly on the selection of the proper solvent system and polymer concentration. ${ }^{39,40}$ As a result, in the present work, several solvents and binary mixtures were tested at different concentrations until fibres were obtained instead of drops. Then, the other electrospinning process parameters such as voltage, flow rate, and needle-collector distance, were optimized to fix the best conditions in order to obtain PBS : DLS 70 : 30 copolymer fibres free of beads and other defects. Mainly $\mathrm{CHCl}_{3}, \mathrm{MeOH}$, DCM, DMF,

Table 3 Mechanical properties of PBS : DLS electrospun fibers from a $25 \mathrm{w} / \mathrm{v} \%$ in $\mathrm{C} \mathrm{CHCl}_{3}: \mathrm{MeOH}$ solution

Mechanical properties PBS : DLS 70 : 30 mat

Young's modulus (MPa)

Ultimate tensile strength (MPa)

Elongation at break (\%)
$24.4 \pm 2.8$

$4.0 \pm 0.4$

$63 \pm 7.0$ 

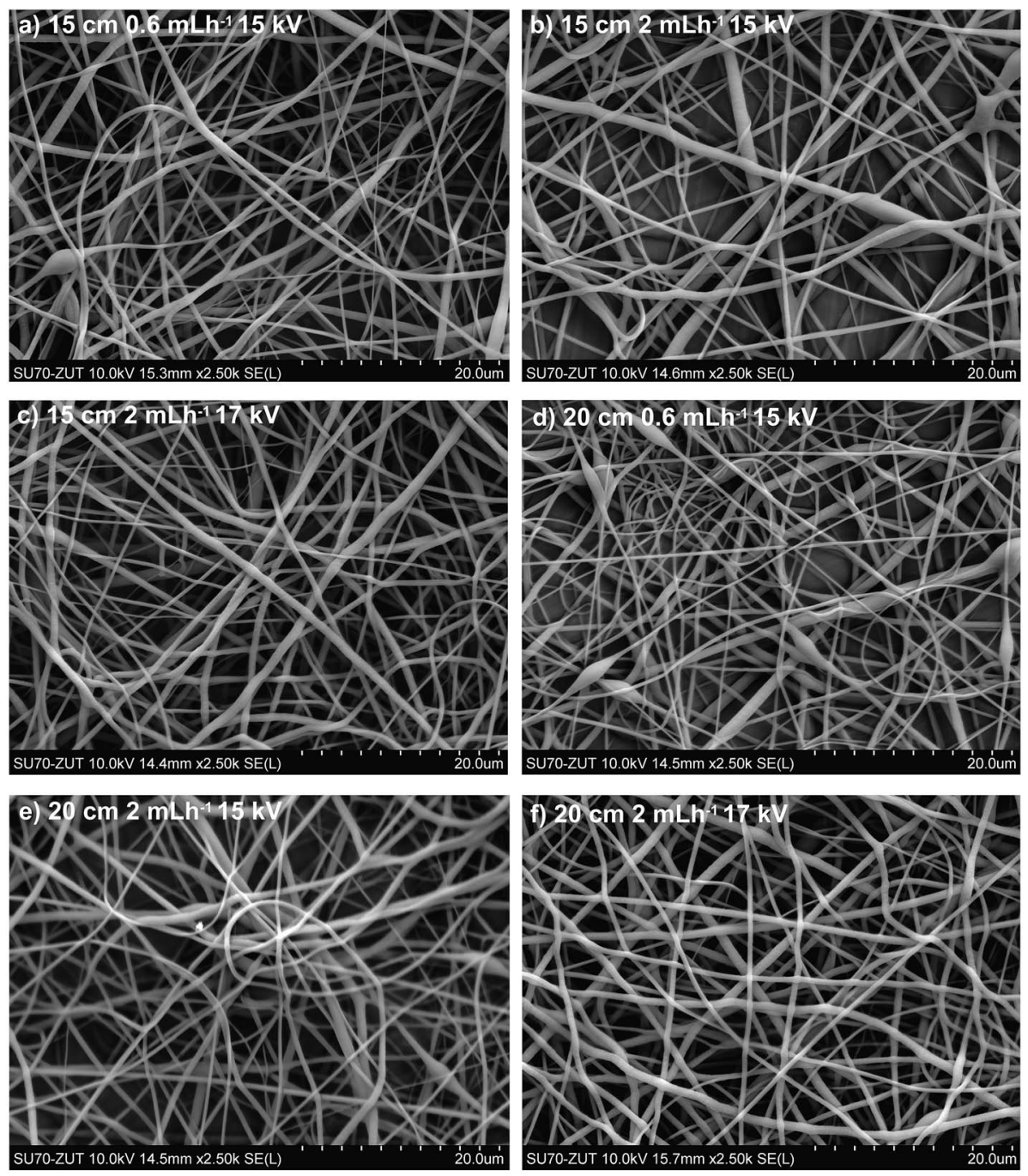

Fig. 3 SEM micrographs of poly(butylene succinate-co-dilinoleic succinate) $70: 30$ copolymer electrospun samples. The polymer concentration was $20 \mathrm{wt} / \mathrm{v} \%$ in a binary mixture of $\mathrm{DCM}: \mathrm{MeOH} 7: 3$ for all the samples. The needle-collector distance, flow rate and voltage conditions were as follows: (a) $15 \mathrm{~cm}, 0.6 \mathrm{~mL} \mathrm{~h}^{-1}, 15 \mathrm{kV}$; (b) $15 \mathrm{~cm}, 2 \mathrm{~mL} \mathrm{~h}^{-1}, 15 \mathrm{kV}$; (c) $15 \mathrm{~cm}, 2 \mathrm{~mL} \mathrm{~h}{ }^{-1}, 17 \mathrm{kV}$; (d) $20 \mathrm{~cm}, 0.6 \mathrm{~mL} \mathrm{~h}$, $15 \mathrm{kV}$; (e) $20 \mathrm{~cm}, 2 \mathrm{~mL}$ $\mathrm{h}^{-1}, 15 \mathrm{kV}$; (f) $20 \mathrm{~cm}, 2 \mathrm{~mL} \mathrm{~h}{ }^{-1}, 17 \mathrm{kV}$.

THF and their binary mixtures were tested. We observed that the copolymer had limited solubility in DMF, THF and their mixtures either with $\mathrm{MeOH}$ and $\mathrm{CHCl}_{3}$, and as a result, the best combinations were the mixtures of either $\mathrm{CHCl}_{3}$ or $\mathrm{MeOH}$ with DCM. Due to the volatility of the DCM, all the tested conditions with the $25 \mathrm{w} / \mathrm{v} \%$ of polymer concentration in DCM : $\mathrm{MeOH}$ mixture clogged the needle. As a result, they were not electrospinnable for sufficient time to achieve a significant amount of fibres. Table 3 summarizes the successful tested electrospun systems using different parameters, concentrations and solvents to study their influence over the final morphology of the obtained fibres and the continuation of the process.

Fig. 3 and 4 illustrate SEM micrographs and diameter distributions of the fibers obtained using DCM : MeOH $7: 3$ (v/ v) mixture as a solvent system. Fig. 5 presents the SEM micrographs and fibre diameter distributions obtained using $\mathrm{CHCl}_{3}$ instead of DCM in the solution. Slight differences in the fibre diameters were observed depending on the electrospinning parameters. Increasing the flow rate from 0.6 to $2 \mathrm{~mL} \mathrm{~h}^{-1}$ while retaining the same voltage and distance $(15 \mathrm{kV}$ and $15 \mathrm{~cm})$, resulted in $25 \%$ greater average fibre diameters (Fig. $4 \mathrm{a} / 5 \mathrm{a}$ and $4 \mathrm{c} / 5 \mathrm{c}$ ), as a larger amount of material flows from the needle tip to the collector. However, increasing the flow rate from 0.6 to 2 $\mathrm{mL} \mathrm{h}^{-1}$ for collector-needle distances of $20 \mathrm{~cm}$ and voltages of $15 \mathrm{kV}$, resulted in beaded fibres with larger diameters and less homogeneous and wider distributions (Fig. $4 \mathrm{~b} / 5 \mathrm{~b}$ and $4 \mathrm{~d} / 5 \mathrm{~d}$ ). These can be due to higher instabilities resulting from the predominant effect of gravitational force over electrical field. The inhomogeneity and beads progressively disappeared with increasing the voltage to $17 \mathrm{kV}$ (Fig. $4 \mathrm{e} / 5 \mathrm{e}$ and $4 \mathrm{f} / 5 \mathrm{f}$ ), i.e. by adjusting the voltage to the flow rate and distance.

In comparison with the DCM : MeOH $7: 3$ solvent system, by using $\mathrm{CHCl}_{3}: \mathrm{MeOH} 7: 3$ mixture enabled electrospinning of higher polymer concentrations $(25 \mathrm{w} / \mathrm{v} \%)$ without clogging the 
a)

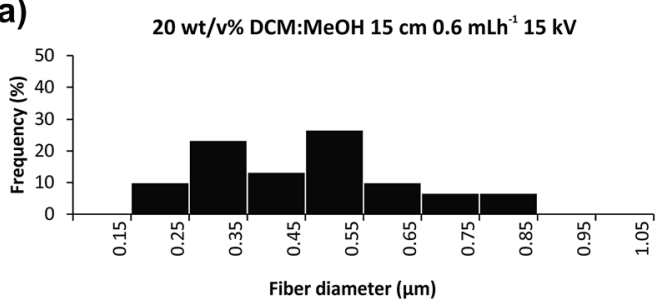

c)

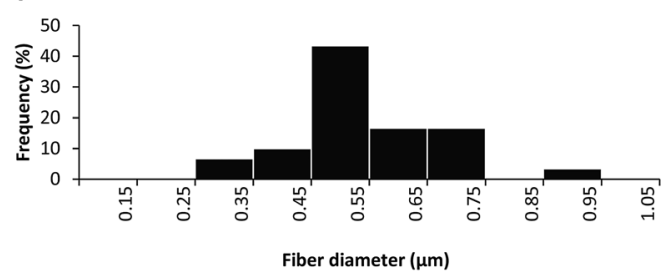

e)

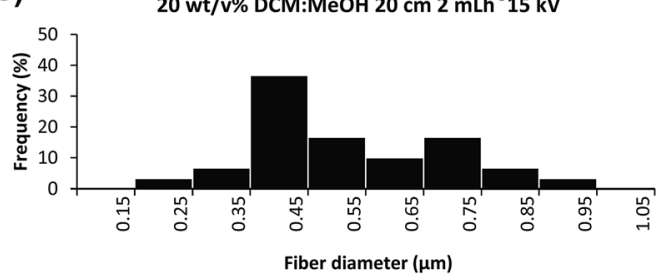

b)

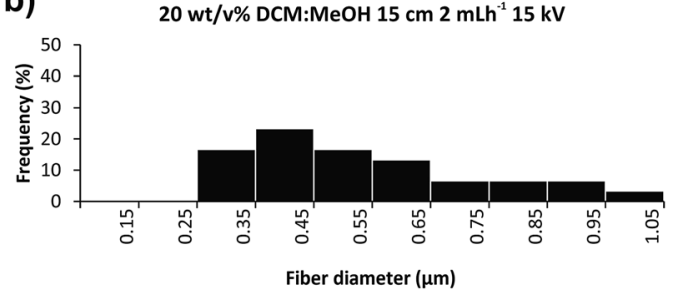

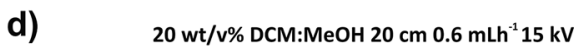

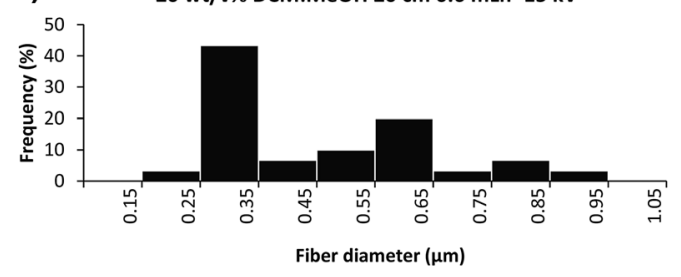

f)

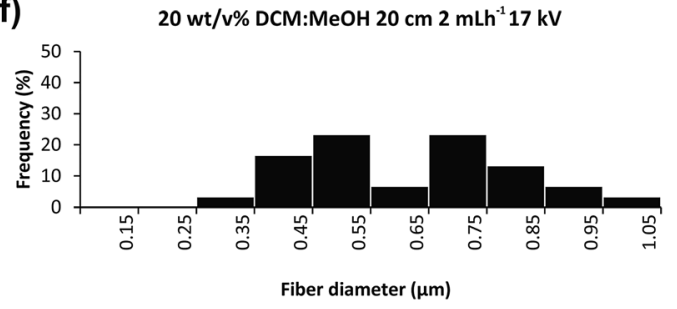

Fig. 4 Diameter distribution obtained from SEM micrographs of poly(butylene succinate-co-dilinoleic succinate) 70 : 30 copolymer electrospun samples. The polymer concentration was $20 \mathrm{wt} / \mathrm{v} \%$ in a binary mixture of DCM : MeOH $7: 3$ for all the samples. The needle-collector distance, flow rate and voltage conditions were: (a) $15 \mathrm{~cm}, 0.6 \mathrm{~mL} \mathrm{~h}^{-1}, 15 \mathrm{kV}$; (b) $15 \mathrm{~cm}, 0.6 \mathrm{~mL} \mathrm{~h}^{-1}, 15 \mathrm{kV}$; (c) $15 \mathrm{~cm}, 2 \mathrm{~mL} \mathrm{~h}$, $17 \mathrm{kV}$; (d) $20 \mathrm{~cm}, 0.6$ $\mathrm{mL} \mathrm{h}-15 \mathrm{kV}$; (e) $20 \mathrm{~cm}, 0.6 \mathrm{~mL} \mathrm{~h}^{-1}, 15 \mathrm{kV}$; (f) $20 \mathrm{~cm}, 2 \mathrm{~mL} \mathrm{~h}{ }^{-1}, 17 \mathrm{kV}$.

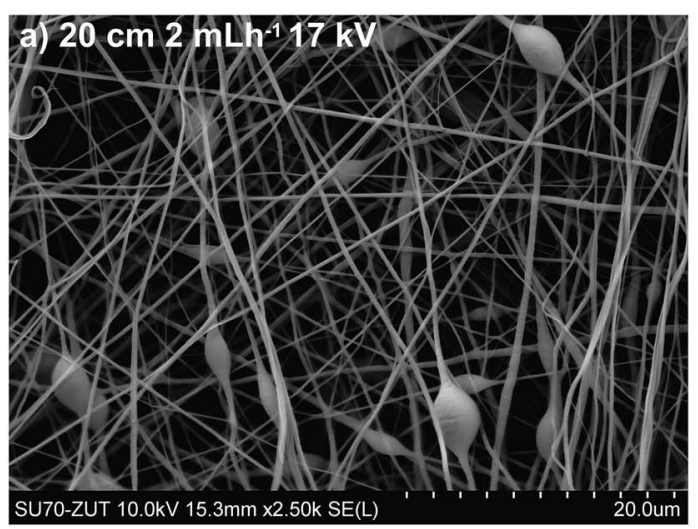

c)

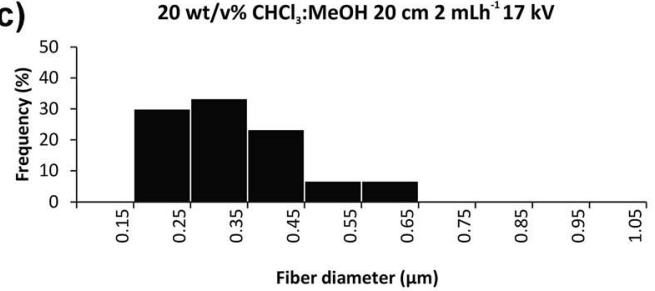

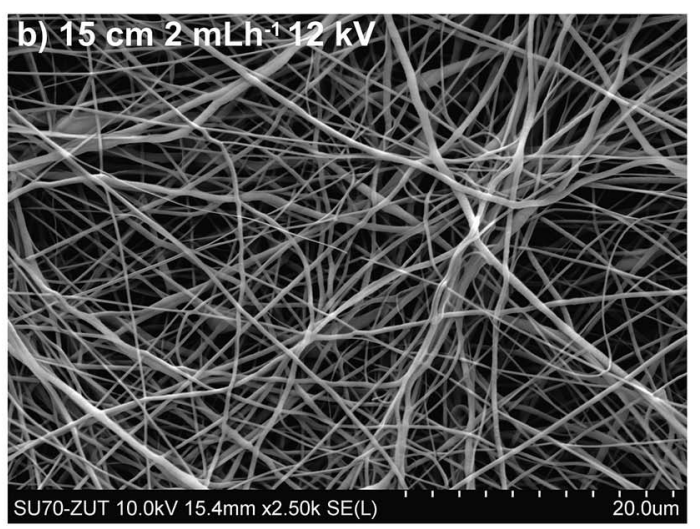

d)

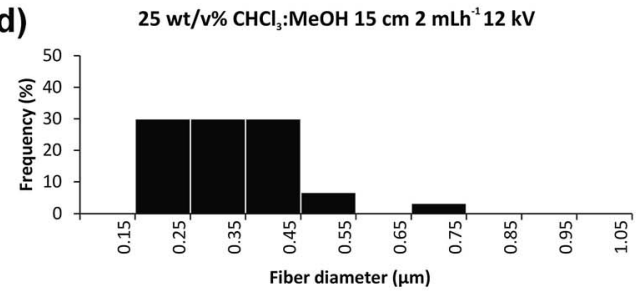

Fig. 5 Top; SEM micrographs of poly(butylene succinate-co-dilinoleic succinate) $70: 30$ copolymer electrospun samples obtained from a binary mixture of $\mathrm{CHCl}_{3}: \mathrm{MeOH} 7: 3$. (a) The polymer concentration was $20 \mathrm{wt} / \mathrm{v} \%$, the needle-collector distance $15 \mathrm{~cm}$, the flow rate $0.6 \mathrm{~mL}$ $\mathrm{h}^{-1}$ and the voltage $15 \mathrm{kV}$; (b) the polymer concentration was $25 \mathrm{wt} / \mathrm{v} \%$, the needle-collector distance $15 \mathrm{~cm}$, the flow rate $2 \mathrm{~mL} \mathrm{~h}^{-1}$ and the voltage $12 \mathrm{kV}$; Bottom; diameter distribution obtained from SEM micrographs of poly(butylene succinate-co-dilinoleic succinate) 70 : 30 copolymer electrospun samples from a binary mixture of $\mathrm{CHCl}_{3}$ : $\mathrm{MeOH} 7: 3$; (c) the polymer concentration was $20 \mathrm{wt} / \mathrm{v} \%$, the needle-collector distance $15 \mathrm{~cm}$, the flow rate $0.6 \mathrm{~mL} \mathrm{~h}^{-1}$ and the voltage $15 \mathrm{kV}$; (d) the polymer concentration was $25 \mathrm{wt} / \mathrm{v} \%$, the needle-collector distance $15 \mathrm{~cm}$, the flow rate $2 \mathrm{~mL} \mathrm{~h}^{-1}$ and the voltage $12 \mathrm{kV}$. 
needle. Using the same polymer concentration and the same conditions as in the DCM : $\mathrm{MeOH} 7: 3$ system, lower average fibre diameters were obtained in case of $\mathrm{CHCl}_{3}: \mathrm{MeOH}$. As can be seen in Fig. 5, for the same polymer concentration $(20 \mathrm{w} / \mathrm{v} \%)$ and electrospinning conditions, the solvent system affects strongly the average fibre diameter, reducing it by half, from $0.631 \pm 0.2 \mu \mathrm{m}$ to $0.335 \pm 0.11 \mu \mathrm{m}$, when $\mathrm{DCM}: \mathrm{CHCl}_{3} 7: 3$ mixture is used instead of DCM : MeOH $7: 3$. However, all the conditions tested with the $20 \mathrm{w} / \mathrm{v} \%$ of polymer in DCM : $\mathrm{CHCl}_{3}$ $7: 3$ resulted in beaded fibers, typically the result of too low concentrations/viscosity. ${ }^{\mathbf{4 1}}$ However, increasing the polymer concentration to $25 \mathrm{w} / \mathrm{v} \%$ in $\mathrm{CHCl}_{3}: \mathrm{MeOH} 7: 3$ (Fig. 5b), resulted in fibres without defects, while retaining smaller diameters $(0.334 \pm 0.11 \mu \mathrm{m})$ and narrower distributions. The optimal conditions to ensure a continuous process and a stable Taylor cone for this higher viscosity solution were found at slightly lower voltage, shorter distance and higher flow rate than for the $20 \mathrm{w} / \mathrm{v} \% \mathrm{DCM}: \mathrm{CHCl}_{3} 7: 3$ solution.

The FTIR spectra of a thicker electrospun mat $(30 \mu \mathrm{m})$ obtained under these optimized conditions (Fig. 2e) showed no marked differences compared to that of the bulk polymer (Fig. 2d), confirming no influence of the electrospinning process or the solvents used on the chemical structure of the copolymer. Likewise, similar thermal properties $\left(T_{\mathrm{g}}, T_{\mathrm{c}}\right.$ and $T_{\mathrm{m}}$ values) were obtained for the electrospun mat and the bulk synthesized material (Table 2 and Fig. S6†), indicating no influence of the process over the material properties.

Regarding the mechanical properties, the values obtained for the enzymatic PBS : DLS 70 : 30 fiber mats are comparable to those reported in the literature for related materials obtained by organometallic catalysis. ${ }^{\mathbf{1 0}, 15}$ Due to the higher presence of hard segments $-70 \mathrm{wt} \%$ in reported material, the fiber mat possesses higher values of Young's modulus $(24.2 \pm 2.8 \mathrm{MPa})$ and maximum tensile strength $(4.0 \pm 0.4 \mathrm{MPa})$, as well as a decrease in the elongation at break $(63 \pm 7.0 \%)$ in comparison with previously reported values for a mat obtained with a related organometallic PBS : DLS material with lower presence of hard segments $(50 \mathrm{wt} \%)$. The correlation between the organometallic and enzymatic systems together with our current research work, open the array of possibilities to obtain copolymers containing DLA-OH soft segments able to cover a wide range of properties by adjusting the hard to soft segments ratio.

\section{Conclusions}

For the first time, Candida antarctica lipase B enzyme (CAL-B) has been used as a catalyst for co-polymerization of diethyl succinate, dimer linoleic diol and 1,4-butanediol. ${ }^{1} \mathrm{H}$ NMR demonstrated that, a copolyester with dilinoleic molecules as the building block for the soft segments was synthesized via enzyme-catalysed polymerization reaction obtaining a poly(butylene succinate-co-dilinoleic succinate) (PBS : DLS) copolymer with a $70: 30 \mathrm{wt} \%$ hard to soft segment ratio via an optimized two-stage synthesis method. During the first reaction step, the method allows for the control of the reaction byproduct, as well as avoiding losses of monomers during the earlier conversion into oligomers. This method facilitates the future reproducibility of the synthesis, as well as the chain growth, during the second, high vacuum step resulting in high molecular weight and good reaction yields. Thermal and chemical characterization of the material showed that its properties were comparable to those obtained by conventional organometallic synthesis. Ongoing experiments in our laboratory indicate that the described synthetic protocol also works for higher amount of DLS soft segments into the PBS : DLS copolymer, while retaining reaction yields $>74 \%$ - these will be reported in the future together with kinetics studies. In addition, we found that optimizing the polymerization method yielded a copolyester with sufficiently high molecular weight to be processed into homogeneous electrospun mats without defects. After the optimization of the electrospinning parameters a thicker mat was obtained and its morphological, mechanical and thermal properties were evaluated. Thanks to the positive results described here, further studies will assess the suitability of these materials for biomedical applications, including cardiac tissue engineering.

\section{Acknowledgements}

This work is financially supported by National Science Centre, Poland, under the HARMONIA scheme (agreement No. UMO2014/14/M/ST8/00610). The authors thank Prof. Judit Puskas and Andrew McClain (The University of Akron) for GPC measurements, and Dr Peter Sobolewski for reviewing the English.

\section{References}

1 M. Vert, Biomacromolecules, 2005, 6, 538-546.

2 P. A. Gunatillake and R. Adhikari, Eur. Cells Mater., 2003, 5, 1-16.

3 W. J. Li and J. A. Cooper, in Biomaterials for Tissue Engineering Applications, ed. J. A. Burdick and R. L. Mauck, Springer Vienna, Vienna, 1st edn, 2011, pp. 47-73.

4 B. P. Chan and K. W. Leong, Eur. Spine J., 2008, 17, 467-479.

5 E. Bressan, V. Favero, C. Gardin, L. Ferroni, L. Iacobellis, L. Favero, V. Vindigni, M. Berengo, S. Sivolella and B. Zavan, Polymers, 2011, 3, 509-526.

6 Y. D. Wang, G. A. Ameer, B. J. Sheppard and R. Langer, Nat. Biotechnol., 2002, 20, 602-606.

7 C. J. Bettinger, Macromol. Biosci., 2011, 11, 467-482.

8 C. L. E. Nijst, J. P. Bruggeman, J. M. Karp, L. Ferreira, A. Zumbuehl, C. J. Bettinger and R. Langer, Biomacromolecules, 2007, 8, 3067-3073.

9 J. Skrobot, L. Zair, M. Ostrowski and M. El Fray, Biomaterials, 2016, 75, 182-192.

10 L. Liverani, A. Piegat, A. Niemczyk, M. El and A. R. Boccaccini, Eur. Polym. J., 2016, 81, 295-306.

11 R. Khosravi, C. A. Best, R. A. Allen, C. E. T. Stowell, E. Onwuka, J. J. Zhuang, Y. U. Lee, T. Yi, M. R. Bersi, T. Shinoka, J. D. Humphrey, Y. Wang and C. K. Breuer, Ann. Biomed. Eng., 2016, 44, 2402-2416.

12 J. Xu and B. H. Guo, Biotechnol. J., 2010, 5, 1149-1163. 
13 L. Wu, R. Mincheva, Y. Xu, J.-M. Raquez and P. Dubois, Biomacromolecules, 2012, 13, 2973-2981.

14 A. Kozlowska, D. Gromadzki, M. El Fray and P. Štěpánek, Fibres Text. East. Eur., 2008, 16, 85-88.

15 M. Tallawi, D. C. Zebrowski, R. Rai, J. A. Roether, D. W. Schubert, M. El Fray, F. B. Engel, K. E. Aifantis and A. R. Boccaccini, Tissue Eng., Part C, 2015, 21, 585-596.

16 N. Jacquel, F. Freyermouth, F. Fenouillot, A. Rousseau, J. P. Pascault, P. Fuertes and R. Saint-Loup, J. Polym. Sci., Part A: Polym. Chem., 2011, 49, 5301-5312.

17 R. A. Gross, M. Ganesh and W. Lu, Trends Biotechnol., 2010, 28, 435-443.

18 J. C. Simitzis, L. T. Zoumpoulakis, S. K. Soulis and L. N. Mendrinos, Microchim. Acta, 2001, 136, 171-174.

19 P. T. Anastas and J. C. Warner, Green chemistry: theory and practice, Oxford University Press, OUP USA, 2000.

20 P. Anastas and N. Eghbali, Chem. Soc. Rev., 2010, 39, 301312.

21 S. Kobayashi and A. Makino, Chem. Rev., 2009, 109, 52885353.

22 S. Kobayashi, H. Uyama and S. Kimura, Chem. Rev., 2001, 101, 3793-3818.

23 I. K. Varma, A. C. Albertsson, R. Rajkhowa and R. K. Srivastava, Prog. Polym. Sci., 2005, 30, 949-981.

24 E. M. Anderson, K. M. Larsson and O. Kirk, Biocatal. Biotransform., 1998, 16, 181-204.

25 H. Uyama and S. Kobayashi, Adv. Polym. Sci., 2006, 194, 133158.

26 H. Uyama, S. Yaguchi and S. Kobayashi, J. Polym. Sci., Part A: Polym. Chem., 1999, 37, 2737-2745.
27 Y. Y. Linko, M. Lämsä, X. Wu, E. Uosukainen, J. Seppälä and P. Linko, J. Biotechnol., 1998, 66, 41-50.

28 A. Mahapatro, B. Kalra, A. Kumar and R. A. Gross, Biomacromolecules, 2003, 4, 544-551.

29 R. K. Srivastava and A. C. Albertsson, Biomacromolecules, 2006, 7, 2531-2538.

30 H. Azim, A. Dekhterman, Z. Jiang and R. A. Gross, Biomacromolecules, 2006, 7, 3093-3097.

31 O. F. Solomon and I. Z. Ciută, J. Appl. Polym. Sci., 1962, 6, 683-686.

32 A. Kumar and R. A. Gross, Biomacromolecules, 2000, 1, 133138.

33 Y. Poojari and S. J. Clarson, Biocatal. Agric. Biotechnol., 2013, 2, 7-11.

34 T. Debuissy, E. Pollet and L. Avérous, Biomacromolecules, 2016, 17, 4054-4063.

35 Z. Yang, X. Zhang, X. Luo, Q. Jiang, J. Liu and Z. Jiang, Macromolecules, 2013, 46, 1743-1753.

36 W. Zhong, in An introduction to Health Care and Medical Textiles, Taylor \& Francis Group, Lancaster, Pensylvania U.S.A., 1st edn, 2013, pp. 37-68.

37 S. Ramakrishna, K. Fujihara, W. E. Teo, T. C. Lim and Z. Ma, An Introduction to Electrospinning and Nanofibers, World Scientific, Singapur, 2005.

38 E. Llorens, L. J. del Valle, R. Ferrán, A. Rodríguez-Galán and J. Puiggalí, J. Polym. Res., 2014, 21, 360.

39 D. Li and Y. Xia, Adv. Mater., 2004, 16, 1151-1170.

40 J. Deitzel, J. Kleinmeyer, D. Harris and N. Beck Tan, Polymer, 2001, 42, 261-272.

41 H. Fong, I. Chun and D. Reneker, Polymer, 1999, 40, 45854592 . 